\title{
Corporate Domination Number of the Cartesian Product of Cycle and Path
}

\author{
S. Padmashini ${ }^{1, *}$, S. Pethanachi Selvam ${ }^{2}$ \\ ${ }^{1}$ Research Scholar, School of Mathematics, Madurai Kamaraj University, Madurai, Tamilnadu, India \\ ${ }^{2}$ Department of Mathematics, The Standard Fireworks Rajaratnam College for Women, Sivakasi, Tamilnadu, India
}

Received October 15, 2020; Revised December 9, 2020; Accepted December 20, 2020

\section{Cite This Paper in the following Citation Styles}

(a):[1]S. Padmashini, S. Pethanachi Selvam,"Corporate Domination Number of the Cartesian Product of Cycle and Path," Mathematics and Statistics, Vol. 9, No. 1, pp. 1 - 7, 2021. DOI: 10.13189/ms.2021.090101.

(b):S. Padmashini, S. Pethanachi Selvam (2021).Corporate Domination Number of the Cartesian Product of Cycle and Path. Mathematics and Statistics, 9(1), 1 - 7. DOI: 10.13189/ms.2021.090101.

Copyright $(2021$ by authors, all rights reserved. Authors agree that this article remains permanently open access under the terms of the Creative Commons Attribution License 4.0 International License

\begin{abstract}
Domination in graphs is to dominate the graph $\mathrm{G}$ by a set of vertices $\mathrm{D}(\subseteq V$, vertex set of $\mathrm{G})$ when each vertex in $G$ is either in $D$ or adjoining to a vertex in $D$. $\mathrm{D}$ is called a perfect dominating set if for each vertex $\mathrm{v}$ is not in $\mathrm{D}$, which is adjacent to exactly one vertex of $D$. We consider the subset $C$ which consists of both vertices and edges. Let $\mathrm{S}(=V \cup E)$ denote the set of all vertices $\mathrm{V}$ and the edges $\mathrm{E}$ of the graph $\mathrm{G}$. Then $\mathrm{C} \subseteq S$ is said to be a corporate dominating set if every vertex $\mathrm{v}$ not in $P \cup Q$ is adjacent to exactly one vertex of $P \cup Q$, where the set $P$ consists of all vertices in the vertex set of an edge induced sub graph $G\left[E_{1}\right],\left(E_{1}\right.$, a subset of $\left.E\right)$ such that there should be maximum one vertex common to any two open neighborhood of different vertices in $V\left(G\left[E_{1}\right]\right)$ and $Q$, the set consists of all vertices in the vertex set $V_{1}$, a subset of $\mathrm{V}$ such that there exists no vertex common to any two open neighborhood of different vertices in $V_{1}$. The corporate domination number of $\mathrm{G}$, denoted by $\gamma_{c o r}(G)$, is the minimum cardinality of elements in C. In this paper, we intend to determine the exact value of corporate domination number for the Cartesian product of the Cycle $C_{4 k}(k \geq 1)$ and Path $P_{n}(n \geq 2)$.
\end{abstract}

Keywords Cartesian Product, Domination, Perfect Dominating Set, Edge-Induced Sub Graph, Corporate Dominating Set, Corporate Domination Number

\section{Introduction}

For graph-theoretic terminology, we have referred to G.
Chartrand, L. Lesniak, and Ping Zhang[2] and Harray[5]. In this paper, all graphs $\mathrm{G}=(\mathrm{V}, \mathrm{E})$ are considered as simple and undirected with vertex set $\mathrm{V}$ and edge set $\mathrm{E}$. The order of $G$ is the number of vertices in the vertex set $V$ and the size of $\mathrm{G}$ is the number of edges in the edge set $\mathrm{E}$. Vertices $u$ and $v$ of $G$ are neighbors if $u v \in E$. The open neighborhood of $v$, denoted by $N(v)$, is the set which consists of all the neighbors of $\mathrm{v}$. The closed neighborhood of $v$, denoted by $N[v]$, consists of all the neighbors of $v$ including the vertex $v$. The complement of the vertex set $S$ is denoted by $S^{c}$. A detailed study of the dominating set and its algorithm of the Cartesian product of paths and cycles have been established by Polana Palvic, Janez Zerovnik [8]. The Cartesian product $G_{1} \square$ $G_{2}$ of graphs $G_{1}$ and $G_{2}$ is a graph with $\mathrm{V}\left(G_{1} \square G_{2}\right)=\mathrm{V}$ $\left(G_{1}\right) \square \mathrm{V}\left(G_{2}\right)$ and $\left(\left(x_{1}, y_{1}\right),\left(x_{2}, y_{2}\right)\right) \in \mathrm{E}\left(G_{1} \square G_{2}\right)$ if and only if either $x_{1}=y_{1}$ and $x_{2}$ adjacent to $y_{2}$ in $G_{2}$ or $x_{2}=y_{2}$ and $x_{1}$ adjacent $y_{1}$ in $G_{1}$.

In [6], the concepts of the variety of domination parameters such as total, perfect, mixed, and many more, have been studied by various authors. Domination with its variations is well studied in [7]. A set $S \subseteq V$ is said to be a dominating set of $G$ if $N[S]=V$. The domination number of $G$, denoted by $\gamma(G)$, is the minimum number of vertices of any dominating set of $G$. In[4] Gayathri A., Abdul. Muneera, Nageswara Rao T., Srinivas Rao T. have explained the significance of domination in various fields and expressed some real-life applications where dominations in a graph are used. In [9] Shobha Shukla, Vikas Singh Thakur have attempted to categorize domination concepts into Some categories. In [1] D. Bange, A. Barkauskas and P. Slater have obtained some 
results of the efficient dominating set.A set $S \subseteq V$ is called an efficient and total efficient dominating set if $|N[v] \cap S|=1$ and $|N(v) \cap S|=1$ for every $v \in V$ respectively. A dominating set $\mathrm{S}$ is perfect if each vertex $v$ is not in $\mathrm{S}$, which is adjacent to exactly one vertex of $\mathrm{S}$. The perfect domination number is the minimum number of vertices of any perfect dominating set and is denoted by $\gamma_{p f}(G)$.Analogous to perfect domination, perfect ev- domination has been introduced in [3] as follows.A set $F$ of edges of a graph $G$ is said to be a perfect ev- dominating set if every vertex of a graph is $\mathrm{m}$-dominated by exactly one edge in $\mathrm{F}$. The perfect ev-domination number of $\mathrm{G}$, denoted by $\gamma_{p e v}(G)$ is the minimum number of edges of any perfect ev- dominating set. By incorporating both perfect and perfect evdomination, the corporate dominating set $\mathrm{C}$ is considered as a subset of $V \cup E$ and also by imposing certain conditions to dominate the graph G. Compared with Perfect domination number $\gamma_{p f}(G)$ and Perfect ev-domination number $\gamma_{p e v}(G)$, the corporate domination number $\gamma_{c o r}(G)$ is minimum.

Corporate domination can be applied practically for the following problem. The CEO of the company has to get approval for a proposal from its board of directors.

Suppose there are 7 board of directors in that company setting at a table as a $\mathrm{C}_{7}$ cycle. The vertices of $\mathrm{C}_{7}$ represent the individual directors whereas the edges between any two vertices denote the trust between the respective two directors. It can be diagrammatically represented in Figure 1.

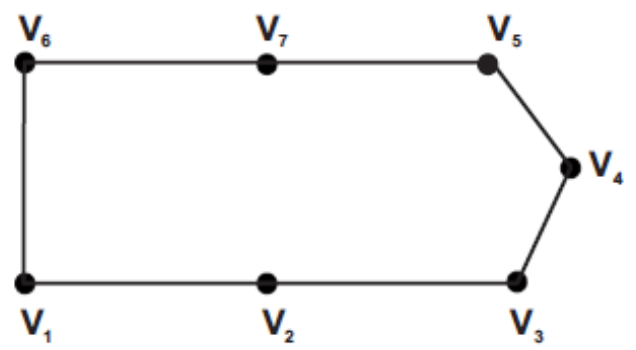

Figure 1. $\quad C=\left\{\mathrm{v}_{7} \mathrm{v}_{1}, \mathrm{v}_{4}\right\}$ and $\gamma_{\text {cor }}\left(\mathrm{C}_{7}\right)=2$

The main aim of the CEO is to select the minimum number of directors to get approval for the proposal. On performing corporate domination, if the $\mathrm{CEO}$ has to select the individual director $\mathrm{v}_{4}$, so that $\mathrm{v}_{4}$ can convince the directors $v_{3}$ and $v_{5}$ as they trust $v_{4}$. Instead of selecting two other individual directors, the CEO can entrust the directors $\mathrm{v}_{1}$ and $\mathrm{v}_{7}$ who are both loyal to each other and can persuade the rest of the directors. Based on this corporate dominating set, graph $\mathrm{C}_{7}$ is dominated and hence the proposal is approved with an optimum solution.

In this paper, we have initiated the study of corporate domination number and have also explained the corporate dominating set with examples. We have found the corporate domination number for the Cartesian product of cycle $C_{4 k}$ and path $P_{n}$ where $k \geq 1, n \geq 2$.

We begin by stating definitions, examples, and Results.

Definition 1.1. A subset of the edges of a graph $G$ together with any vertices that are their endpoints is said to be an edge - induced sub graph of $G$ and is denoted by $[E]$.

The graph $G$ and $G\left[E_{1}\right]$, an edge induced sub graph of $E_{1}$ where $E_{1}=\left\{v_{1} v_{5}, v_{4} v_{5}, v_{2} v_{3}\right\} \subseteq E$, are shown in Figure 2.
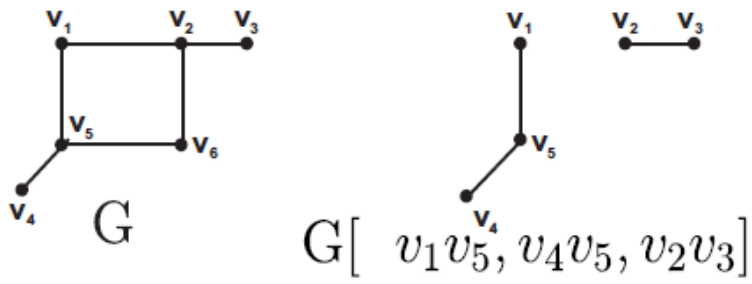

Figure 2. $G$ and $G\left[E_{1}\right]$

Definition 1.2 Let $G(=V, E)$ be a graph. Let $C=V_{1} \cup E_{1}(\subseteq V \cup E) . \quad$ Take $\quad P=\left\{u \in V\left(G\left[E_{1}\right]\right) /\right.$ $|N(u) \cap N(w)| \leq 1$ for all $w(\neq u) \in$ $\left.V\left(G\left[E_{1}\right]\right)\right\}$ where $V\left(G\left[E_{1}\right]\right)$ denote the vertex set of an edge induced subgraph $G\left[E_{1}\right]$ and $Q=\{v \in$ $V_{1} / N(v) \cap N(w)=\varphi$ forall $\left.w(\neq v) \in V_{1}\right\}$. A subset $\mathrm{C}$ is said to be a corporate dominating set if every vertex $v \notin P \cup Q$ is adjacent to exactly one vertex of $P \cup Q$. The corporate domination number of $\mathrm{G}$, denoted by $\gamma_{\text {cor }}(G)$, is the minimum cardinality of elements in C.

For a graph $\mathrm{G}$ which is given in Figure 3, $\gamma_{\text {cor }}(G)=2$. Here $\mathrm{E}_{1}=\left\{v_{2} v_{3}\right\}, \mathrm{V}\left(\mathrm{G}\left[\mathrm{E}_{1}\right]\right)=\left\{v_{2}, v_{3}\right\}$ and $\mathrm{C}=\left\{v_{2} v_{3}\right.$, $\left.v_{6}\right\}$

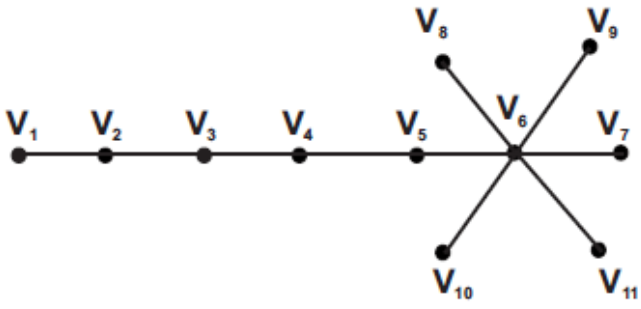

$G$

Figure 3. $\mathrm{C}=\left\{v_{2} v_{3}, v_{6}\right\}$ and $\gamma_{\text {cor }}(G)=2$.

Proposition 1.3Let $\mathrm{G}$ be a graph. Then $\gamma_{c o r}(\mathrm{G})=1$ if and only if one of the following holds.

i There exists a full degree vertex in G.

ii There exists an edge $u v$ in $\mathrm{G}$ such that uv does not lie on any triangle and $d(u)+d(v)=n$.

Remark 1.4 Corporate domination need not exist for all graphs.

Example 1.5The 4-regular graph $G$ in Figure 4 does not have a corporate dominating set. 


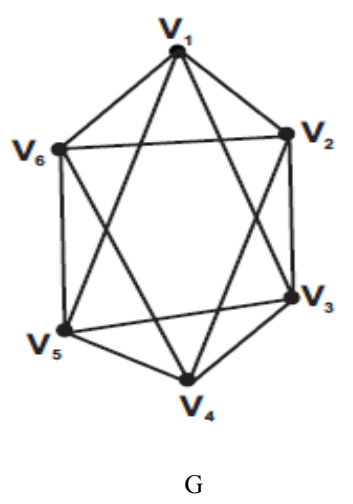

Figure 4. $\gamma_{c o r}(\mathrm{G})$ does not exist

If we take $\mathrm{C}=\left\{v_{i}\right\}, 1 \leq i \leq 6$, or $C=\left\{v_{i} v_{j}\right\}$, $1 \leq i, j \leq 6, i \neq j$, then by using Proposition 1.3, the graph $G$ does not have a corporate dominating set. Let $C$ be the corporate dominating set with $|C| \geq 2$. Then $|P \cup Q| \geq 2$. But any two vertices in this graph have a common neighbor, which is a contradiction.

Proposition 1.6 Let $\mathrm{C}$ be a corporate dominating set with $\mathrm{C}=\mathrm{V}_{1}$. Then

i Every corporate dominating set is the dominating set as well as the perfect dominating set.

ii Both dominating and perfect dominating set need not be the corporate dominating set.

Example 1.7Consider the cycle $C_{6}$. V $\left(C_{6}\right)=$ $\left\{v_{1}, v_{2}, v_{3}, v_{4}, v_{5}, v_{6}\right\}$. Then the corporate dominating set $\mathrm{C}=\left\{v_{2}, v_{5}\right\}$ is also the dominating set as well as the perfect dominating set.

\section{Proposition 1.8}

i). For any cycle $C_{m}$ with $m \geq 3, \gamma_{\text {cor }}\left(C_{m}\right)=\left[\frac{m}{4}\right\rceil$.

ii). For any Path $P_{n}$ with $n \geq 2, \gamma_{\text {cor }}\left(P_{n}\right)=\left\lceil\frac{n}{4}\right\rceil$.

iii). For any complete graph $\mathrm{Kn}(\mathrm{n} \geq 3), \gamma_{\text {cor }}(\mathrm{Kn})=1$.

iv). For any $\mathrm{n} \geq 2, \gamma_{\text {cor }}(\mathrm{K} 1, \mathrm{n})=1$.

v). For any wheel graph $\mathrm{W}_{\mathrm{n}}(\mathrm{n}>3), \gamma_{c o r}\left(\mathrm{~W}_{\mathrm{n}}\right)=1$.

\section{Results on Corporate Domination}

Inthis section, we establish $\gamma_{c o r}\left(C_{4 k} \square P_{\mathrm{n}}\right)$ with illustrations.

Theorem 2.1 Let $\mathrm{C}_{4 \mathrm{k}}(\mathrm{k} \geq 2)$ be any cycle and $\mathrm{P}_{2 \mathrm{n}+1}(\mathrm{n} \geq 1)$ be any path. Then

$$
\gamma_{\text {cor }}\left(\mathrm{C}_{4 \mathrm{k}} \square \mathrm{P}_{2 \mathrm{n}+1}\right)=\mathrm{k}\left\lceil\frac{2 n+1}{2}\right\rceil .
$$

Proof:Let $C_{4 k}(k \geq 2)$ be any cycle and $P_{2 n+1}(n \geq 1)$ be any path and let $\mathrm{m}=4 \mathrm{k}$. Consider the following cases.

Case $1:$ Let $n \equiv 0(\bmod 2)$.

For $0 \leq s \leq 2 n$ and $2 \leq \mathrm{t} \leq 2(\mathrm{n}-1)$ where $\mathrm{s} \equiv 0(\bmod 4)$ and $\mathrm{t} \equiv 2(\bmod 4)$ and $0 \leq \mathrm{i} \leq \frac{m}{4}-1$ and $1 \leq \mathrm{j} \leq \frac{m}{4}-1$, let

$$
\mathrm{C}=\left\{v_{s m+4 i+2} v_{s m+4 i+3}, v_{t m+1} v_{(t+1) m}, v_{t m+4 j} v_{t m+4 j+1}\right\}
$$

Here, $P=$

$\left\{v_{s m+4 i+2}, v_{s m+4 i+3}, v_{t m+1}, v_{(t+1) m}, v_{t m+4 j}, v_{t m+4 j+1}\right\}$ an $\mathrm{d} \mathrm{Q}=\varphi$. Since for every $u \in(P \cup Q)^{c}, N(u) \cap(P \cup$ $Q)=\{w\}$ where $w \in P \cup Q, C$ is the corporate dominating set. Since $|Q|=0,|P|=|P \cup Q|=\left(\frac{m}{4}+\right.$ $\left.\frac{m}{4}\right)\left[\left(\frac{2 n}{4}+1\right)+\left(\frac{2 n}{4}\right)\right]=\left(\frac{m}{2}\right)\left\lceil\frac{2 n+1}{2}\right\rceil$.

\section{Hence $|\mathrm{C}|=\left(\frac{m}{4}\right)\left\lceil\frac{2 n+1}{2}\right\rceil=k\left\lceil\frac{2 n+1}{2}\right\rceil$.}

To prove $\mathrm{C}$ is minimum, let $C^{\prime}$ be any other corporate dominating set and $P^{\prime}, Q^{\prime}$ be the sets corresponding to $C^{\prime}$ such that every vertex in $\left(P^{\prime} \cup Q^{\prime}\right)^{c}$ is adjacent to exactly one vertex in $P^{\prime} \cup Q^{\prime}$. Furthermore, the set $C^{\prime}$ will be in one of the following forms.

i). $C^{\prime}=V_{1}^{\prime}$

ii). $C^{\prime}=E_{1}^{\prime}$

iii). $C^{\prime}=V_{1}{ }^{\prime} \cup E_{1}^{\prime}$.

If $C^{\prime}=V_{1}^{\prime}$ holds, then $P^{\prime}=\varphi$ and $Q^{\prime} \neq \varphi$. Since for any $u \in V_{1}^{\prime}, N(u) \cap N(w) \neq \varphi$ for some $w \in V_{1}{ }^{\prime}$ which is a contradiction.

If $C^{\prime}=E_{1}^{\prime}$ holds, then $P^{\prime} \neq \varphi$ and $Q^{\prime}=\varphi$. Let $\left|P^{\prime}\right| \geq|P| \quad$ with $\quad\left|P^{\prime}\right| \leq m\left\lceil\frac{2 n+1}{3}\right\rceil$. Thus $\left|C^{\prime}\right| \leq$ $m\left\lceil\frac{2 n+1}{3}\right]$ and hence $\left|C^{\prime}\right| \geq|C|$.

If $C^{\prime}=V_{1}{ }^{\prime} \cup E_{1}^{\prime}$ holds, then $P^{\prime} \neq \varphi$ and $Q^{\prime} \neq \varphi$. Suppose $\left|P^{\prime} \cup Q^{\prime}\right|<|P \cup Q|$. Then there exists at least one vertex $u \in\left(P^{\prime} \cup Q^{\prime}\right)^{c}$ which is not adjacent to any one of the vertices in $P^{\prime} \cup Q^{\prime}$. This is a contradiction. Hence $\left|P^{\prime} \cup Q^{\prime}\right| \geq|P \cup Q|$.

a) Let $\left|P^{\prime}\right| \leq|P|$ and $\left|Q^{\prime}\right|>|Q|$ with $4 \leq\left|P^{\prime}\right| \leq$ $\left(\frac{m}{2}\right)\left\lceil\frac{2 n+1}{2}\right\rceil$ and $2 \leq\left|Q^{\prime}\right| \leq 2\left\lceil\frac{2 n+1}{3}\right\rceil$. Then $E^{\prime}$ contains at most $\left(\frac{m}{2}-3\right)\left\lceil\frac{2 n+1}{2}\right\rceil$ edges and $V^{\prime}$ contains at most $2\left\lceil\frac{2 n+1}{3}\right\rceil$ vertices.

Hence $\left|C^{\prime}\right| \leq\left(\frac{m}{2}-3\right)\left\lceil\frac{2 n+1}{2}\right\rceil+2\left\lceil\frac{2 n+1}{3}\right\rceil$.

b) Suppose $\left|P^{\prime}\right|>|P|$ and $\left|Q^{\prime}\right|>|Q| \operatorname{with}\left(\frac{m}{2}\right)\left[\frac{2 n+1}{2}\right]+$ $1 \leq\left|P^{\prime}\right| \leq m\left\lceil\frac{2 n+1}{3}\right\rceil-1$ and $1 \leq\left|Q^{\prime}\right| \leq 2\left\lceil\frac{2 n+1}{3}\right\rceil$.

Hence $\quad\left|C^{\prime}\right| \leq m\left\lceil\frac{2 n+1}{3}\right\rceil-2+2\left\lceil\frac{2 n+1}{3}\right\rceil=(m+$ 2) $\left\lceil\frac{2 n+1}{3} \mid-2\right.$. Thus, $\left|C^{\prime}\right| \geq|C|$.

Case 2 : Let $n \equiv 1(\bmod 2)$ and $m=4 k$.

For $0 \leq s \leq 2(n-1)$ and $2 \leq t \leq 2 n$ where $s \equiv 0(\bmod 4)$ and $t \equiv 2(\bmod 4)$ and $0 \leq i \leq \frac{m}{4}-$ 1 and $1 \leq j \leq \frac{m}{4}-1$

let $\mathrm{C}=\left\{v_{s m+4 i+2} v_{s m+4 i+3}, v_{t m+1} v_{(t+1) m}, v_{t m+4 j} v_{t m+4 j+1}\right\}$ Here,

$P=$

$\left\{v_{s m+4 i+2}, v_{s m+4 i+3}, v_{t m+1}, v_{(t+1) m}, v_{t m+4 j}, v_{t m+4 j+1}\right\}$ ， 
$Q=\varphi$

Since for any $v \in(P \cup Q)^{c}, N(v) \cap(P \cup$ $Q)=\{\mathrm{w}\}$ where $w \in P \cup Q, \mathrm{C}$ is the corporate dominating set. Proceed as in Case 1, $\mathrm{C}$ is the minimum corporate dominating set and $|C|=k\left[\frac{2 n+1}{2}\right]$.

In particular, for $k=1, \gamma_{c o r}\left(C_{4} \square P_{2 n+1}\right)=\left\lceil\frac{2 n+1}{2}\right\rceil$. As the proof for proving minimum in Theorem, 2.1 is different from the proof of Theorem 2.2, we provide a separate theorem for $k=1$.

Theorem 2.2 Let $C_{4}$ be a cycle and $P_{2 n+1}(n \geq 1)$ be any path.Then $\gamma_{\text {cor }}\left(C_{4} \square P_{2 n+1}\right)=\left\lceil\frac{2 n+1}{2}\right\rceil$.

Proof:Let $C_{4}$ be a cycle and $P_{2 n+1}(n \geq 1)$ be any path.

For $0 \leq i \leq\left\lfloor\frac{n}{2}\right\rfloor$ and $0 \leq j \leq\left\lceil\frac{n}{2}\right\rceil-1 \quad$ let $C=$ $\left\{v_{16 i+2} v_{16 i+3}, v_{16 j+9} v_{16 j+12}\right\}$.

By using theorem 2.1, $|\mathrm{C}|=\left\lceil\frac{2 n+1}{2}\right\rceil$.

To prove $\mathrm{C}$ is minimum, let $C^{\prime}$ be any other corporate dominating set and $P^{\prime}, Q^{\prime}$ be the sets corresponding to $C^{\prime} \quad$ such that every vertex in $\left(P^{\prime} \cup Q^{\prime}\right)^{c}$ is adjacent to exactly one vertex in $P^{\prime} \cup Q^{\prime}$. Furthermore, the $\operatorname{set} C^{\prime}$ will be in one of the following forms.
i). $C^{\prime}=V_{1}^{\prime}$
ii). $C^{\prime}=E_{1}^{\prime}$
iii). $C^{\prime}=V_{1}^{\prime} \cup E_{1}^{\prime}$

If $C^{\prime}=V_{1}^{\prime}$ holds, then $P^{\prime}=\varphi$ and $Q^{\prime} \neq \varphi$. Since for any $u \in V_{1}{ }^{\prime}, N(u) \cap N(w) \neq \varphi$ for some $w \in V_{1}{ }^{\prime}$ which is a contradiction.

If $C^{\prime}=E_{1}^{\prime}$ holds, then $P^{\prime} \neq \varphi$ and $Q^{\prime}=\varphi$. Since for any $v \in P^{\prime},|N(v) \cap N(\mathrm{w})|>1$ for some $w \in P^{\prime}$ which is a contradiction.

If $C^{\prime}=V_{1}{ }^{\prime} \cup E_{1}^{\prime}$ holds, then $P^{\prime} \neq \varphi$ and $Q^{\prime} \neq \varphi$.

If $\left|P^{\prime} \cup Q^{\prime}\right|>|P \cup Q|$, then $\left|N\left(v_{i}\right) \cap\left(P^{\prime} \cup Q^{\prime}\right)\right|>1$ for some $v_{i} \in\left(P^{\prime} \cup Q^{\prime}\right)^{c}$, a contradiction. Let $\left|P^{\prime} \cup Q^{\prime}\right|<$ $|P \cup Q|$. Then there exists at least one vertex $u \in$ $\left(P^{\prime} \cup Q^{\prime}\right)^{c}$ which is not adjacent to any one of the vertices in $P^{\prime} \cup Q^{\prime}$. This is a contradiction. Hence $\left|P^{\prime} \cup Q^{\prime}\right|=|P \cup Q|$.

Let $\left|P^{\prime}\right|<|P|$ and $\left|Q^{\prime}\right|>|Q|$ with $2 \leq\left|P^{\prime}\right| \leq$ $2 n$ and $2 \leq\left|Q^{\prime}\right| \leq 2\left\lceil\frac{2 n+1}{3}\right\rceil$. Then $E_{1}^{\prime}$ contains at most $\frac{2 n}{2}$ edges and $V_{1}^{\prime}$ contains at most $2\left\lceil\frac{2 n+1}{3}\right\rceil$ vertices. Hence $\left|C^{\prime}\right| \leq \frac{2 n}{2}+2\left\lceil\frac{2 n+1}{3}\right\rceil$. Thus $\left|C^{\prime}\right| \geq|C|$.

Suppose $\left|P^{\prime}\right| \geq|P|$ and $\left|Q^{\prime}\right|>|Q|$. This is impossible, since $\left|P^{\prime} \cup Q^{\prime}\right|=|P \cup Q|$.

Hence $\mathrm{C}$ is the minimum corporate dominating set and $\gamma_{\text {cor }}\left(C_{4} \square P_{2 n+1}\right)=\left\lceil\frac{2 n+1}{2}\right\rceil$.

\section{Illustration 2.3}

In Figure 5, let $\mathrm{C}=\left\{v_{2} v_{3}, v_{9} v_{12}, v_{18} v_{19}, v_{25} v_{28}\right\}$. Since for any $u \in(\mathrm{P} \cup \mathrm{Q})^{c}, \mathrm{~N}(\mathrm{u}) \cap(\mathrm{P} \cup \mathrm{Q})=\{\mathrm{w}\}$ where $w \in P \cup Q, \mathrm{C}$ is the corporate dominating set and $\gamma_{\text {cor }}\left(C_{4} \square P_{7}\right)=4$.

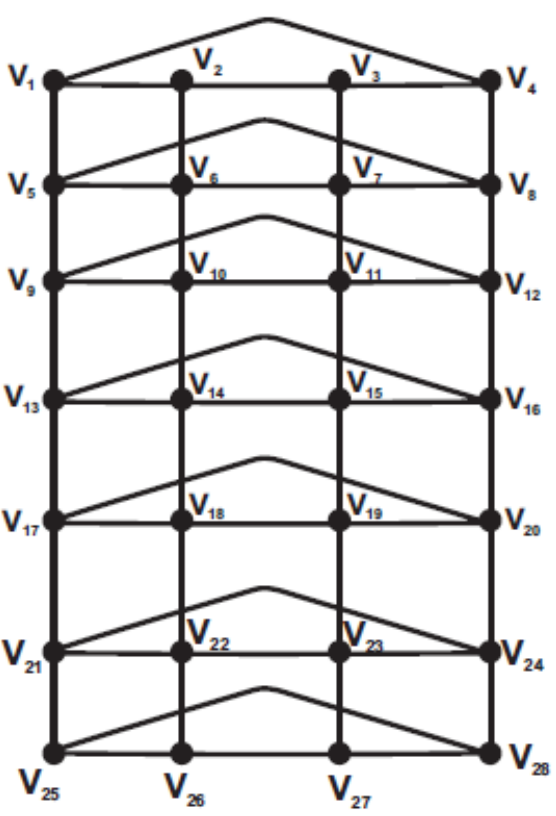

Figure 5. $C_{4} \square P_{7}$

Theorem 2.4 Let $C_{4 k}(k \geq 2)$ be any cycle and $P_{2 n}(n \geq 1)$ be any path. Then

$$
\gamma_{c o r}\left(C_{4 k} \square P_{2 n}\right)=\left\{\begin{array}{cc}
\frac{4 k n}{3} & \text { if } k \equiv 0(\bmod 3) \\
2 k\left\lceil\frac{2 n}{3}\right\rceil & \text { otherwise }
\end{array}\right.
$$

Proof.

Let $\mathrm{C}_{4 \mathrm{k}}(\mathrm{k} \geq 2)$ be any cycle and $\mathrm{P}_{2 \mathrm{n}} \quad(\mathrm{n} \geq 1)$ be any path . Let $\mathrm{m}=4 \mathrm{k}$. Consider the following cases.

Case 1 : Let $k \equiv 0(\bmod 3)$.

For $2 \leq \mathrm{i} \leq \mathrm{m}-1$ where $\mathrm{i} \equiv 2(\bmod 3)$,

let $\mathrm{C}=\left\{v_{i} v_{m+i}, v_{2 m+i} v_{3 m+i}, \ldots, v_{m n-4 m+i} v_{m n-3 m+i}, v_{m n-2 m+i}\right.$ $\left.v_{m n-m+i}\right\}$

Here $\mathrm{P}=\left\{v_{i}, v_{m+i}, v_{2 m+i}, v_{3 m+i}, \ldots, v_{m n-4 m+i}, v_{m n-3 m+i}\right.$, $\left.v_{m n-2 m+i}, v_{m n-m+i}\right\}$ and $\mathrm{Q}=\varphi$

Since for any $\mathrm{u} \epsilon(P \cup Q)^{c}, \mathrm{~N}(\mathrm{u}) \cap(\mathrm{P} \cup \mathrm{Q})=\{\mathrm{w}\}$ where $\mathrm{W} \in \mathrm{P} \cup \mathrm{Q}, \mathrm{C}$ is the corporate dominating set. Since $|\mathrm{Q}|=$ 0 and every vertex in $\mathrm{P} \cup \mathrm{Q}$ is adjacent to exactly two vertices in $(P \cup Q)^{c},|\mathrm{P}|=|\mathrm{P} \cup \mathrm{Q}|=\left(\frac{m-3}{3}+1\right) 2 \mathrm{n}=\frac{2 m n}{3}$. Hence $C$ contains $\frac{m n}{3}$ edges. Thus, $|\mathrm{C}|=\frac{m n}{3}=\frac{4 k n}{3}$.

We shall prove that $\mathrm{C}$ is the minimum. Let $\mathrm{C}^{\prime}$ be any other corporate dominating set and $\mathrm{P}^{\prime}, \mathrm{Q}^{\prime}$ be the sets corresponding to $\mathrm{C}^{\prime}$ such that every vertex in $\left(\mathrm{P}^{\prime} \cup \mathrm{Q}^{\prime}\right)^{c}$ is adjacent to exactly one vertex in $P^{\prime} \cup Q^{\prime}$. Furthermore, the set $C^{\prime}$ will be in one of the following forms.

i). $C^{\prime}=V_{1}{ }^{\prime}$

ii). $C^{\prime}=E_{1}^{\prime}$

iii). $C^{\prime}=V_{1}^{\prime} \cup E_{1}^{\prime}$

If $C^{\prime}=V_{1}^{\prime}$ holds, then $\mathrm{P}^{\prime}=\varphi$ and $\mathrm{Q}^{\prime} \neq \varphi$. This happens only if $n=1$. 
Clearly, $\left|\mathrm{C}^{\prime}\right|=\frac{4 k}{3}$. Hence $\left|\mathrm{C}^{\prime}\right| \geq|\mathrm{C}|$.

If $C^{\prime}=E_{1}^{\prime}$ holds, then $P^{\prime} \neq \varphi$ and $\mathrm{Q}^{\prime}=\varphi$. Let $\left|\mathrm{P}^{\prime}\right| \geq|\mathrm{P}|$ with $\left|\mathrm{P}^{\prime}\right| \leq m\left\lceil\frac{2 n}{3}\right\rceil$ and $\left|\mathrm{Q}^{\prime}\right|=0$. Thus $\left|\mathrm{C}^{\prime}\right| \leq m\left\lceil\frac{2 n}{3}\right\rceil$ and hence $\left|C^{\prime}\right| \geq|C|$.

If $C^{\prime}=V_{1}^{\prime} \cup E_{1}^{\prime}$ holds, then $P^{\prime} \neq \varphi$ and $Q^{\prime} \neq \varphi$. Suppose $\left|P^{\prime} \cup Q^{\prime}\right|<\frac{2 m n}{3}$. Then there exists at least one vertex $v_{i} \epsilon\left(P^{\prime} \cup Q^{\prime}\right)^{c}$ which is not adjacent to any one of the vertices in $P^{\prime} \cup Q^{\prime}$. This is a contradiction.

Hence $\left|\mathrm{P}^{\prime} \cup \mathrm{Q}^{\prime}\right| \geq|\mathrm{P} \cup \mathrm{Q}|\left(=\frac{2 m n}{3}\right)$

a) Let $\left|\mathrm{P}^{\prime}\right|<|\mathrm{P}|$ and $\left|\mathrm{Q}^{\prime}\right|>|\mathrm{Q}|$ with $\frac{2 m n-2 m}{3} \leq\left|\mathrm{P}^{\prime}\right| \leq$ $\frac{2 m n}{3}-1$ and $1 \leq\left|\mathrm{Q}^{\prime}\right| \leq \frac{2 m}{3}$. Clearly, $\left|E_{1}{ }^{\prime}\right| \leq \frac{2 m n}{3}-2$ and $\left|V_{1}{ }^{\prime}\right| \leq \frac{2 m}{3}$.

Hence $\left|\mathrm{C}^{\prime}\right| \leq \frac{2 m n-2 m-6}{3}$.

b) Suppose $\left|\mathrm{P}^{\prime}\right|^{3} \geq|\mathrm{P}|$ and $\left|\mathrm{Q}^{\prime}\right|>|\mathrm{Q}|$ with $\frac{2 m n}{3} \leq\left|\mathrm{P}^{\prime}\right| \leq$ $m\left\lceil\frac{2 n}{3}\right\rceil-1$ and $1 \leq\left|\mathrm{Q}^{\prime}\right| \leq \frac{2 m}{3}$. Then $\left|\mathrm{C}^{\prime}\right| \leq \mathrm{m}\left\lceil\frac{2 n}{3}\right\rceil-1+$ $\frac{2 m}{3}$.

Hence $\left|\mathrm{C}^{\prime}\right| \geq|\mathrm{C}|$.

Case 2 : Let $k \not \equiv 0(\bmod 3)$ and let $m=4 k$.

Subcase $2.1:$ Let $2 n \equiv 0(\bmod 3)$.

For $1 \leq t \leq 2 n-2$ where $\mathrm{t} \equiv 1(\bmod 3)$,

let $\mathrm{C}=\left\{\mathrm{v}_{\mathrm{tm}+1} \mathrm{~V}_{\mathrm{tm}+2}, \mathrm{v}_{\mathrm{tm}+3} \mathrm{v}_{\mathrm{tm}+4}, \ldots, \mathrm{v}_{(\mathrm{t}+1) \mathrm{m}-1} \mathrm{v}_{(\mathrm{t}+1) \mathrm{m}}\right\}$.

Here $P=\left\{v_{t m+1}, v_{t m+2}, v_{t m+3}, v_{t m+4}, \ldots, v_{(t+1) m-1}, v_{(t+1) m}\right\}$ and $\mathrm{Q}=\varphi$

Since every vertex not in $\mathrm{P} \cup \mathrm{Q}$ is adjacent to exactly one vertex in $\mathrm{P} \cup \mathrm{Q}, \mathrm{C}$ is the corporate dominating set .

As every vertex in $\mathrm{P} \cup \mathrm{Q}$ is adjacent to exactly two vertices in $(P \cup Q)^{c},|\mathrm{P}|=|\mathrm{P} \cup \mathrm{Q}|=\left(\frac{2 n-3}{3}+1\right) \mathrm{m}=$ $\mathrm{m}\left(\frac{2 n}{3}\right)$. Hence $\mathrm{C}$ contains $\left(\frac{m}{2}\right)\left(\frac{2 n}{3}\right)\left(=2 \mathrm{k}\left(\frac{2 n}{3}\right)\right)$ edges.

To prove $\mathrm{C}$ is minimum, let $\mathrm{C}^{\prime}$ be any other corporate dominating set and $\mathrm{P}^{\prime}, \mathrm{Q}^{\prime}$ be the sets corresponding to $\mathrm{Q}^{\prime}$ such that, $\left|N(u) \cap\left(P^{\prime} \cup Q^{\prime}\right)\right|=1, \forall u \in\left(P^{\prime} \cup Q^{\prime}\right)^{c}$. Furthermore, the set $C^{\prime}$ will be in one of the following forms.

i). $C^{\prime}=V_{1}{ }^{\prime}$

ii). $C^{\prime}=E_{1}^{\prime}$

iii). $C^{\prime}=V_{1}{ }^{\prime} \cup E_{1}^{\prime}$

If (i)holds, then $\mathrm{P}^{\prime}=\varphi$ and $\mathrm{Q}^{\prime} \neq \varphi$. Since for any $\mathrm{u} \epsilon V^{\prime}{ }_{1}, \mathrm{~N}(\mathrm{u}) \cap \mathrm{N}(\mathrm{w}) \neq \varphi$ for some $\mathrm{w} \epsilon V^{\prime}{ }_{1}$, which is a contradiction.

If (ii)holds, then $\mathrm{P}^{\prime} \neq \varphi$ and $\mathrm{Q}^{\prime}=\varphi$. Let $\left|\mathrm{P}^{\prime}\right| \geq|\mathrm{P}|$ with $\mid$ $\mathrm{P}^{\prime} \mid=\frac{2 m n}{3}$. Then $\left|\mathrm{C}^{\prime}\right| \leq \frac{2 m n}{3}$ and hence $\left|\mathrm{C}^{\prime}\right| \geq|\mathrm{C}|$.

If (iii) holds, then $\mathrm{P}^{\prime} \neq \varphi$ and $\mathrm{Q}^{\prime} \neq \varphi$.

If $\left|P^{\prime} \cup Q^{\prime}\right|>|P \cup Q|$, then $\left|N\left(v_{i}\right) \cap\left(P^{\prime} \cup Q^{\prime}\right)\right|>$ 1 for some $v_{i} \epsilon\left(\mathrm{P}^{\prime} \cup \mathrm{Q}^{\prime}\right)^{c}$, a contradiction. Suppose $\left|P^{\prime} \cup Q^{\prime}\right|<|\mathrm{P} \cup \mathrm{Q}|$. Then there exists at least one vertex $v_{i} \in\left(\mathrm{P}^{\prime} \cup \mathrm{Q}^{\prime}\right)^{c}$ which is not adjacent to any one of the vertices in $P^{\prime} \cup Q^{\prime}$ which is a contradiction. Hence $\left|P^{\prime} \cup Q^{\prime}\right|=|P \cup Q|=\frac{2 m n}{3}$.

a) Let $\left|\mathrm{P}^{\prime}\right|<|\mathrm{P}|$ and $\left|\mathrm{Q}^{\prime}\right|>|\mathrm{Q}|$ with $(\mathrm{m}-2)\left(\frac{2 n}{3}\right) \leq\left|\mathrm{P}^{\prime}\right| \leq$ $\frac{2 m n}{3}-1$ and $1 \leq\left|\mathrm{Q}^{\prime}\right| \leq 4\left(\frac{n}{3}\right)$. Then $\mathrm{C}^{\prime}$ contains at most $\frac{2 m n}{3}-2$ edges and $4\left(\frac{n}{3}\right)$ vertices. Hence $\left|\mathrm{C}^{\prime}\right| \leq(\mathrm{m}$ $+2)\left(\frac{2 n}{3}\right)-2$. Thus $\left|\mathrm{C}^{\prime}\right| \geq|\mathrm{C}|$.

b) Suppose $\left|\mathrm{P}^{\prime}\right| \geq|\mathrm{P}|$ and $\left|\mathrm{Q}^{\prime}\right|>|\mathrm{Q}|$. This is impossible, since $\left|\mathrm{P}^{\prime} \cup \mathrm{Q}^{\prime}\right|=|\mathrm{P} \cup \mathrm{Q}|$.

Subcase $2.2:$ Let $2 \mathrm{n} \equiv 1(\bmod 3)$.

For $0 \leq t \leq 2 n-1$ where $t \equiv 0(\bmod 3)$,

let $\mathrm{C}=\left\{\mathrm{v}_{\mathrm{tm}+1} \mathrm{v}_{\mathrm{tm}+2}, \mathrm{v}_{\mathrm{tm}+3} \mathrm{v}_{\mathrm{tm}+4}, \ldots, \mathrm{v}_{(\mathrm{t}+1) \mathrm{m}-1} \mathrm{v}_{(\mathrm{t}+1) \mathrm{m}}\right\}$.

Proceeding the similar argument which is used in the Subcase 2.1 , we can prove that $\mathrm{C}$ is the corporate dominating set and $|\mathrm{P} \cup \mathrm{Q}|=\left(\frac{2 n-1}{3}+1\right) \mathrm{m}=\mathrm{m}\left\lceil\frac{2 n}{3}\right\rceil$. Hence $|\mathrm{C}|=\left(\frac{m}{2}\right)\left\lceil\frac{2 n}{3}\right\rceil=2 \mathrm{k}\left\lceil\frac{2 n}{3}\right\rceil$. We shall prove that $\mathrm{C}$ is minimum. Replace $\left(\frac{2 n}{3}\right)$ by $\left\lceil\frac{2 n}{3}\right\rceil$ in subcase2.1, $\left|\mathrm{C}^{\prime}\right| \geq|\mathrm{C}|$.

Subcase 2.3 : Let $2 \mathrm{n} \equiv 2(\bmod 3)$.

For $0 \leq t \leq 2 n-2$ where $t \equiv 0(\bmod 3)$, let $\mathrm{C}=\left\{\mathrm{v}_{\mathrm{tm}+1} \mathrm{v}_{\mathrm{tm}+2}, \mathrm{v}_{\mathrm{tm}+3} \mathrm{v}_{\mathrm{tm}+4}, \ldots, \mathrm{v}_{(\mathrm{t}+1) \mathrm{m}-1} \mathrm{v}_{(\mathrm{t}+1) \mathrm{m}}\right\}$.

By the similar argument which is used in Subcase2.2, we can prove that $\mathrm{C}$ is the corporate dominating set and $\mathrm{C}^{\prime}|\geq| \mathrm{C} \mid$.

From all the above cases, $\gamma_{c o r}\left(C_{4 k} \square P_{2 n}\right)=2 k\left\lceil\frac{2 n}{3}\right\rceil$.

\section{Illustration 2.5 .}

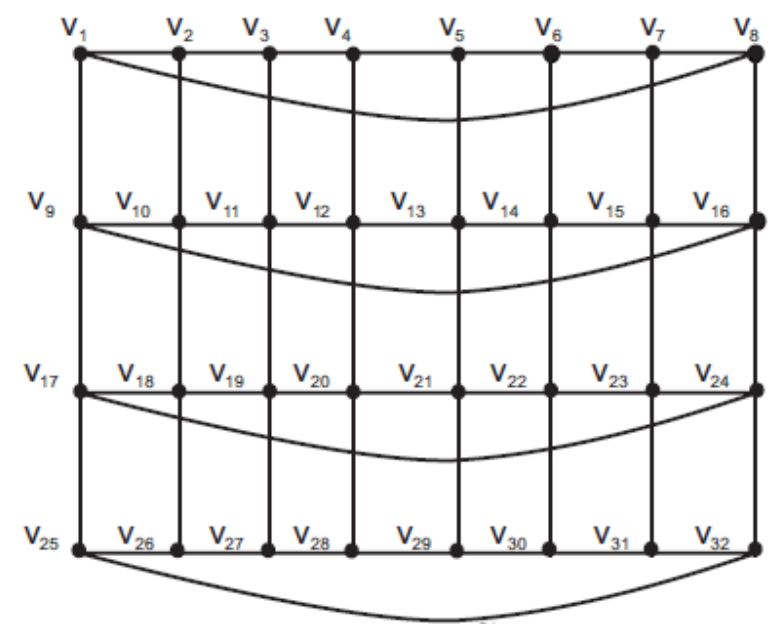

Figure 6. $C_{8} \square P_{4}$

In the Figure $6, \mathrm{k} \equiv 2(\bmod 3)$ and $2 \mathrm{n} \equiv 1(\bmod 3)$. $\mathrm{C}=\left\{v_{1} v_{2}, v_{3} v_{4}, v_{5} v_{6}, v_{7} v_{8}, v_{25} v_{26}, v_{27} v_{28}, v_{29} v_{30}, v_{31} v_{32}\right\}$ and $\gamma_{c o r}\left(C_{8} \square P_{4}\right)=8$. 


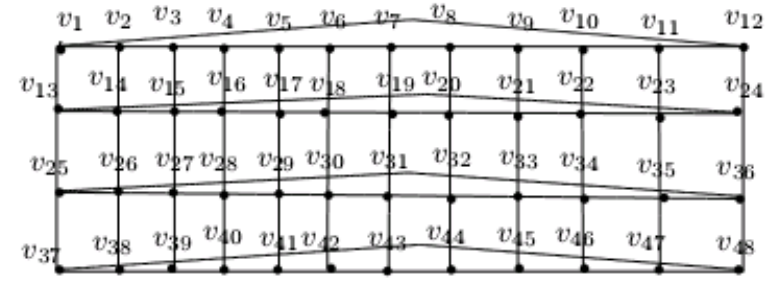

Figure 7. $C_{12} \square P_{4}$

In Figure $7, \mathrm{k} \equiv 0(\bmod 3) . \mathrm{C}=$

$\left\{v_{2} v_{14}, v_{26} v_{38}, v_{5} v_{17}, v_{29} v_{41}, v_{8} v_{20}, v_{32} v_{44}, v_{11} v_{23}, v_{35} v_{47}\right\}$ and $\gamma_{\text {cor }}\left(C_{12} \square P_{4}\right)=8$.

Proposition 2.6. Let $C_{4}$ be a cycle and $P_{2 n}(n \geq 1)$ be any path. Then $\gamma_{c o r}\left(C_{4} \square P_{2 n}\right)=3\left\lceil\frac{2 n}{3}\right\rceil$.

Proof. Let $C_{4}$ be a cycle and $P_{2 n}(n \geq 1)$ be any path.

Consider the following cases.

Case 1 : Let $2 n \equiv 0(\bmod 3)$.

For $1 \leq t \leq 2 n-2$ where $t \equiv 1(\bmod 3)$, let $C=$ $\left\{v_{4 t+1} v_{4 t+2}, v_{4 t+3}, v_{4 t+4}\right\}$.

Clearly, $|Q|=2\left(\frac{2 n-3}{3}+1\right)=2\left(\frac{2 n}{3}\right)$.

Since every vertex not in $P \cup Q$ is adjacent to exactly one vertex in $\cup Q, C$ is the corporate dominating set.

As every vertex in $P \cup Q$ is adjacent to exactly two vertices in $(P \cup Q)^{c},|P \cup Q|=2\left(\frac{2 n-3}{3}+1\right)+2\left(\frac{2 n}{3}\right)=$ $4\left(\frac{2 n}{3}\right)$ and $|C|=\left(\frac{2 n}{3}\right)+4\left(\frac{n}{3}\right)$. Hence $C$ contains $6\left(\frac{n}{3}\right)(=2 n)$ edges.

We shall prove that $C$ is the minimum. Let $C^{\prime}$ be any other corporate dominating set. Proceed as in Theorem 2.2, $C^{\prime}=V_{1}^{\prime}$ and $C^{\prime}=E_{1}^{\prime}$ are impossible. If $C^{\prime}=V_{1}{ }^{\prime} U$ $E_{1}^{\prime}$ holds, then $P^{\prime} \neq \varphi$ and $Q^{\prime} \neq \varphi$. We have to prove that $\left|P^{\prime}\right|=|P|$ and $\left|Q^{\prime}\right|=|Q|$. If not, then $\mid N\left(v_{i}\right) \cap$ $\left(P^{\prime} \cup Q^{\prime}\right) \mid>1$ for some $v_{i} \in\left(P^{\prime} \cup Q^{\prime}\right)^{c}$ orthere exists at least one vertex $u \in\left(P^{\prime} \cup Q^{\prime}\right)^{c}$ which is not adjacent to any one of the vertices in $P^{\prime} \cup Q^{\prime}$. This is a contradiction. Hence $\left|C^{\prime}\right|=|C|=3\left(\frac{2 n}{3}\right)$ and $\mathrm{C}$ is the minimum corporate dominating set.

Case 2 : Let $2 n \equiv 1(\bmod 3)$.

For $0 \leq t \leq 2 n-1$ where $t \equiv 0(\bmod 3)$, let $C=$ $\left\{v_{4 t+1} v_{4 t+2}, v_{4 t+3}, v_{4 t+4}\right\}$.

As every vertex in $P \cup Q$ is adjacent to exactly two vertices in $(P \cup Q)^{c},|P \cup Q|=2\left(\frac{2 n-1}{3}+1\right)+$ $2\left(\frac{2 n-1}{3}+1\right)=4\left\lceil\frac{2 n}{3}\right\rceil$. Proceed as in Case $1, C$ is the corporate dominating set and $|C|=3\left\lceil\frac{2 n}{3}\right\rceil$.

We shall prove that $C$ is the minimum. Replace $\left(\frac{2 n}{3}\right)$ by $\left\lceil\frac{2 n}{3}\right\rceil$ in Case 1, C is the minimum.

Case3: Let $2 n \equiv 2(\bmod 3)$.
For $0 \leq t \leq 2 n-2$ where $t \equiv 0(\bmod 3)$, let $C=$ $\left\{v_{4 t+1} v_{4 t+2}, v_{4 t+3}, v_{4 t+4}\right\}$.

By the similar argument in Case 2, C is the minimum corporate dominating set and $|C|=3\left[\frac{2 n}{3}\right]$. From all the above cases, $\gamma_{\text {cor }}\left(C_{4} \square P_{2 n}\right)=3\left\lceil\frac{2 n}{3}\right\rceil$.

\section{Conclusions}

We have studied the new domination parameter namely, corporate domination, and explained the concepts with illustrations. The corporate domination number for some standard classes of graphs such as Path, Cycle, Wheel, Star, and Complete graphs has been computed. Also, we have found out that the exact value of the corporate domination number for the Cartesian product of $\mathrm{C}_{4 \mathrm{k}}$ and $\mathrm{P}_{\mathrm{n}}$ where $k \geq 1$ and $n \geq 2$ and illustrated the same with examples. Due to the minimum cardinality of the corporate dominating set, it can be beneficial when applied practically than perfect and perfect ev- domination. Further the general case for getting the corporate domination number for $\mathrm{C}_{\mathrm{m}} \square \mathrm{P}_{\mathrm{n}}$ wherem $\neq 4 k$ and $n \geq 2$, $C_{m} \square C_{n}(m, n \geq 3)$, and $\mathrm{P}_{\mathrm{m}} \square \mathrm{P}_{\mathrm{n}}(m, n \geq 2)$ can be investigated.

\section{Acknowledgement}

The authors would like to thank the referees for their valuable comments and suggestions that have helped us to improve the research work.

\section{REFERENCES}

[1] Bange D., Barkauskas A. and Slater P., "Efficient Dominating sets in Graphs," in Applications of Discrete Math, R. D. Ringeisen and F.S. Roberts, eds., SIAM, Philad, 1998, pp.189- 199.

[2] Chartrand G., Lesniak L. and Ping Zhang,"Matchings, Factorization and Domination,"in Graphs and Digraphs, Fifth Edition, CRCPress, 2010, pp. 438-445.

[3] Chitra S., Prabhavathi N., "A Study of Perfect edge, Perfect edge covering and Perfect edge vertex domination sets in Graphs," InternationalJournal of Research and Analytical Reviews, Vol 7, pp.408-415, 2020.http://www.ijrar.org/pap ers/IJRAR2001330.pdf

[4] Gayathri A., Abdul. Muneera, Nageswara Rao T., Srinivas Rao T., " Study Of Various Dominations in Graph Theory And Its Applications," International Journal Of Scientific \& Technology Research, Vol 9, pp.3426-3429, 2020. https://www.ijstr.org/research-paper-publishing.php?month $=$ feb 2020

[5] Harray F., "Graphs,"in Graph theory, Adison - Wesley, 
Reading, Massachuselts, 1972, pp. 8-25.

[6] Haynes T. W., Hedetniemi S .T. and Slater P. J., "Domination Parameters of a Graph,"in Domination in graphs Advanced topics, Marcel Dekker.inc, New York , 1999, pp. 271-300 .

[7] Kulli V. R., in Theory of dominationin graphs, Vishwa International Publication,2010, pp. 1-284.

[8] Polana Palvic, Janez Zerovnik, “A Note on the Domination number of the Cartesian Product of Paths and Cycles," Krangujevac Journal of Mathematics., vol. 37, no. 2, pp.275-285,2013.https://imi.pmf.kg.ac.rs/kjm/pub/1386200 3212535_13861659366327_7.pdf

[9] Shobha Shukla, Vikas Singh Thakur, " Domination And It's Type in Graph Theory,"Journal of Emerging Technologies and Innovative Research,Vol.7,pp.1549-1557,2020.http://w ww.jetir.org/papers/JETIR2003225.pdf 